\title{
Testes preliminares para o controle da podridào negra da pupunha (Bactris gasipaes) (1)
}

\author{
Maria Luiza Braz Alves ( ${ }^{2}$ ) \\ Wanders B. Chavez Flores ${ }^{(2}$ ]
}

\section{Resumo}

Procurando determinar a concentração de esporos do fungo Thielaviopsis paradoxa agente etiológico de podridão negra em frutos de pupunha (Bactris gasipaes H.B.K.), inocularam-se frutos com e sem pedúnculo nas concentrações de $10^{7}, 20^{5}, 10^{3}, 10^{1}$ esporos $/ \mathrm{ml}$. Osservou-se que os frutos que apresentam pedúnculo neses. sitam de uma concentração de $10^{7}$ esporos $/ \mathrm{ml}$ para que $100 \%$ destes sejam infectados. Os que apresentaram pedúnculo e sementes foram mais sensíveis à infecção. No controle in vitro testaram-se os fungicidas Benomyl, Triadimefon, Zineb e Maneb a 25, 50, 75 e 100ppm em meio BDA. A melhor eficiência no controle de doença foi obtida com Benomyl em todas as concentrações estudadas, Triadimefon não foi eficiente a $100 \mathrm{ppm}$ e os demais fungicidas não controlaram o crescimento do fungo.

\section{INTRODUÇÃo}

A pupunheira é uma palmeira tropical de elevado valor nutritivo, sendo conhecida e cultivada há muito tempo por inúmeras tribos indígenas da América Central e do Sul (Camacho, 1972). Apesar de ser uma cultura antiga, a origem desta espécie ainda é bastante discutida e países como o Panamá, Colômbia, Equador, Peru e Bolívia são citados como sendo os prováveis centros de origem (Fournier, 1961; Popenoe \& Jimenes, 1921; Seibert, 1950).

Os indígenas, segundo Patiño (1958), utilizavam todas as partes da planta: as folhas serviam de palha para cobertura de suas tendas, o tronco para o fabrico de armas e implementos agrícolas, as inflorescências para alimentação, o fruto cozido e seco para fabricação de farinhas e bebidas fermentadas e o meristema central como palmito. Atualmente o fruto cozido e com sal constitui a principal forma de consumo, sendo muito ricos em carboidratos, cálcio, ferro, fósforo, vitamina A e proteínas (INCAP e ICNND, 1964).

A comercialização da pupunha é feita através de cachos que possui normalmente 50 a 300 frutos. Um dos maiores problemas para a comercialização decorre do fato de que estes frutos não possuem boa capacidade de armazenamento, pois estão sujeitos a uma podridão, que se caracteriza por iniciar com uma podridão suave da polpa do fruto e num estágio mais avançado da doença adquire uma coloração negra. Esta enfermidade, cujo agente causal é o fungo Thielaviopsis paradoxa $\left({ }^{3}\right)$, foi anteriormente constatada em Costa Rica (Vargas \& Vilaplana, 1979). No entanto, nenhuma referência bibliográfica sobre o ataque deste fungo nos frutos da pupunha foi encontrada em literatura nacional, sendo portanto este o primeiro relato desta doença, efetuado no Brasil.

O objetivo deste trabalho foi o de determinar a concentração de esporos capaz de reproduzir os sintomas de podridão dos frutos de testar in vitro qual o (s) fungicida (s) que inibe o crescimento do fungo em meio de cultura. Estas informações básicas servirão para determinação de um controle preventivo e curativo da enfermidade do fruto da pupunheira em trabalhos. posteriores.

\section{MATERIAIS E MÉTOdos}

Os frutos de pupunha foram colhidos na área de fruticultura do INPA, (Km 45 - BR-174) e selecionados para o teste em laboratório.

(1) - Realizado com apoio do POLAMAZONIA.

(2) - Instituto Nacional de Pesquisas da Amazônia. Manaus.

(3) - Espécie gentilmente confirmada por Dr. H. Bolkan - Universidade de Brasília-DF. 
Após confirmação da doença, o fungo isolado de frutos infectados naturalmente foi mantido em tubo de ensaio com meio BDA (Batata-Dextrose-Agar) inclinado. Para obtenção de inóculos o fungo foi transferido para 10 placas de Petri, e incubados a $28^{\circ} \mathrm{C}$ por 8 dias. As suspensões de conídios foram obtidas da superfície das placas com o auxílio de um pincel. Em seguida, foram filtradas através de gaze, separando-se a maior quantidade possível de micélio do fungo. As concentrações de esporos foram determinadas microscopicamente com o auxílio de um hemacitômetro, ajustando-se com água estéril para as concentrações de $10^{1}, 10^{3}, 10^{5}, 10^{7}$ esporos $/ \mathrm{ml}$.

$\mathrm{Na}$ inoculação, utilizaram-se 5 frutos com presença e ausência de pedúnculos para cada concentração e como testemunha, utilizaram-se os frutos inoculados em água estéril. Os frutos foram inoculados pincelando-se o local de inserção do pedúnculo e mantidos em caixa de madeira revestida por papel kraft. Em seguida, as caixas de madeiras foram cobertas com plásticos e os frutos foram mantidos nesta câmara úmida por 24 horas à temperatura ambiente $\left(25-29^{\circ} \mathrm{C}\right)$. A avaliação do grau de infecção dos frutos foi efetuada, 8 dias após inoculação.

Para a avaliação da inibição de crescimento de Thielaviopsis paradoxa, in vitro, foram utilizados os seguintes fungicidas: Benomyl, Triadimefon, Zineb e Maneb. As concentrações - estoque de cada fungicida foram preparadas, separadamente, em água esterilizada, sendo adicionadas alíquotas pré-determinadas de cada fungicida ao meio BDA fundente (45$47^{\circ} \mathrm{C}$ ), obtendo-se $0 ; 25 ; 50 ; 75$ e $100 \mathrm{ppm}$ de princípio ativo dos mesmos.

Após solidificação do meio-de-cultura, cada placa (15 ml meio/placa) foi inoculada com um disco de micélio, de $T$. paradoxa, de $4 \mathrm{~mm}$ de diâmetro obtido através de um vasador de rolha. O T. paradoxa inoculado tinha uma semana de crescimento em meio BDA a temperatura de laboratório $\left(25-28^{\circ} \mathrm{C}\right)$.

A avaliação foi encerrada aos 8 dias após a repicagem para as placas quando o crescimento do fungo com ausência de fungicidas atingiu as bordas da placa. O ensaio foi mon- tado seguindo o delineamento experimental de blocos ao acaso com parcelas subdivididas, sendo que nas parcelas estavam os fungicidas e nas subparcelas as concentrações destes, com 4 repetições.

\section{Resultados E DISCUSSÃo}

Os frutos sem pedúnculo tanto os inoculados como os não inoculados, apresentaram um alto grau de infecção em todas as concentrações testadas. A retirada do pedúnculo, facilita a penetração do patógeno, pois a polpa fica em contato direto com o ambiente externo, podendo o patógeno penetrar e colonizar rapidamente o hospedeiro.

As concentrações $10^{\circ}$ e $10^{1}$ esporos $/ \mathrm{ml}$ não diferiram estatisticamente entre si (gráfico 1), assim como as concentrações de $10^{3}$ e $10^{7}$ esporos $/ \mathrm{ml}$. No entanto as duas últimas concentrações diferiram de $10^{\circ}$ e $10^{1}$ espo$\mathrm{ros} / \mathrm{ml}$. Todas as concentrações diferiram estatisticamente da concentração $10^{5}$ esporos/ $\mathrm{ml}$. Esta concentração apresentou a menor média de frutos infectados, face ao grande número de frutos sem sementes inoculados. A presença ou ausência de sementes nos frutos não foi um caráter considerado durante a montagem do experimento porém, observou-se que a ausência de sementes influenciou nos resultados obtidos, pois verificou-se que os frutos sem sementes parecem ser mais tolerantes à infecção. Esta tolerância talvez se deva ao

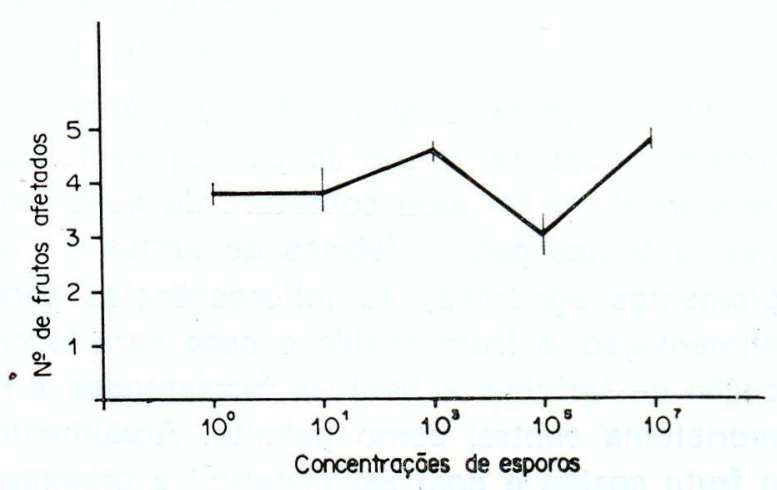

Gráfico 1 - Dados médios de 5 amostras, por tratamento, de frutos de pupunha, sem $p=d u ́ n-$ culo, infectados, com intervalos de confiança de desvio padrão (95\%). 
aumento da área de atuação do patógeno, desacelerando a colonização do tecido do hospedeiro, ou talvez, ainda, pela presença de alguma substância química presente nestes frutos.

Entretanto, ao testar frutos com pedúnculo observou-se que o grau de infecção aumentou linearmente em função das concentrações de esporos. As concentrações $10^{3}$ e $10^{5}$ espo$\mathrm{ros} / \mathrm{ml}$ não diferiram estatisticamente entre si (gráfico 2), mas diferem das concentrações $10^{7}$ e $10^{1}$ esporos $/ \mathrm{ml}$. Somente na concentração de $10^{7}$ esporos $/ \mathrm{ml}$ foram constatados $100 \%$ de infecção dos frutos testados. Em abacaxi, ao testarem diferentes concentrações deste inóculo nos frutos, também não foi observada diferença significativa entre as concentrações $10^{3}$ e $10^{5}$ esporos $/ \mathrm{ml}$ (Aguillar et al., 1981).

O produto químico Benomyl inibiu totalmente o desenvolvimento do fungo nas 4 concentrações testadas. Em testes posteriores foram avaliadas menores concentrações deste fungicida e verificou-se que o desenvolvimento do fungo é nulo em concentrações de 20 , 15, 10 e 5 ppm deste princípio ativo. O Triadimefon causou uma pequena redução no desenvolvimento deste fungo. A concentração de $100 \mathrm{ppm}$ de Triadimefon diferiu estatisticamente das demais concentrações deste produto. (Tabela 2). Os fungicidas Zineb e Maneb mostraram-se totalmente ineficientes em todas as concentrações testadas, não sendo detectada diferença estatística entre si e nem entre as diferentes concentrações. Aguillar et al. (1981), ao testar diferentes produtos quimicos visando ao controle curativo e preventivo da podridão negra em abacaxi verificou que o fungicida Triadimefon foi o mais eficiente para o controle da doença, em que Benomyl se mostrou ineficiente, resultados estes, contrastantes com os obtidos neste teste in vitro para o mesmo fungo. No entanto Cho et al. (1977) em testes anteriores, tinham observado uma eficiência relativa do produto Benomyl para o controle da podridão negra em abacaxi.

Apesar de Triadimefon não ter sido eficaz no controle do desenvolvimento do fungo, observou-se uma alteração fenotípica na coloração da colônia passando de preta para esverdeada. Possivelmente, esta mudança de coloração pode alterar a patogenicidade do fungo para os frutos.

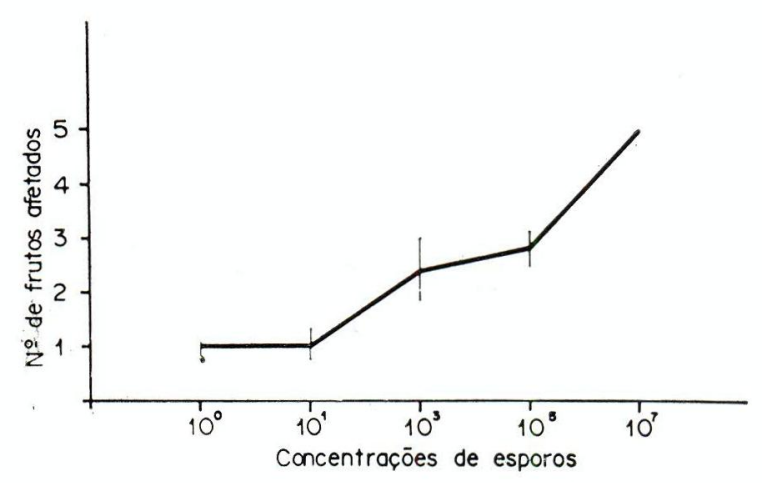

Gráfico 2 - Dados médios de 5 amostras, por tratamento, de frutos de pupunha, sem pedúnculo, infectados, com intervalos de confiança de desvio padrão (95\%).

TABELA 1 - Efeito da concentração de inóculo de Thielaviopsis sp. sobre frutos de pupunha com pecíolo e sem pecíolo,

\begin{tabular}{ccc}
\hline $\begin{array}{c}\text { Concentrações de } \\
\text { esporos/ml }\end{array}$ & \multicolumn{2}{c}{ Média de frutos de pupunha infectados } \\
\cline { 2 - 3 } & Frutos com Pecíolo & Frutos sem Pecíolo \\
$10^{0}$ & $1,0 \pm 0,26^{*}$ & $3,8 \pm 0,17$ \\
$10^{1}$ & $1,0 \pm 0,26$ & $3,8 \pm 0,41$ \\
$10^{3}$ & $2,4 \pm 0,57$ & $4,6 \pm 0,21$ \\
$10^{5}$ & $2,8 \pm 0,32$ & $3,0 \pm 0,37$ \\
$10^{7}$ & $5,0 \pm 0$ & $4,8 \pm 0,17$
\end{tabular}

(*) - Intervalo de confiança calculado a partir do disvio padrão. 
TABELA 2 - Valores médios de raio $(\mathrm{cm})$ de colônias de Thielaviopsis sp. sob o efeito de quatro fungicidas.

\begin{tabular}{|c|c|c|c|c|c|c|}
\hline \multirow[t]{2}{*}{ Fungicidas } & \multicolumn{6}{|c|}{ Concentrações (ppm) } \\
\hline & 25 & 50 & 75 & 100 & Médial & \\
\hline Benomyl & $0,0 \quad a^{*} x$ & $0,0 \quad a x^{* *}$ & 0,0 ax & 0,0 ax & $0,0 x$ & \\
\hline Triadimefon & 4,58 ay & 4,62 ay & 4,36 ay & 2,48 by & $4,01 y$ & \\
\hline Zineb & 8,72 az & 8,66 az & 8,70 az & 8,70 az & $8,69 z$ & \\
\hline Maneb & $8,70 \mathrm{az}$ & $8,68 \mathrm{az}$ & 8,70 az & 8,68 az & $8,69 \mathrm{z}$ & \\
\hline Testemunha & - & - & - & - & - & 8,72 \\
\hline Média & 5,50 & 5,49 & 5,44 & 4,97 & & \\
\hline C.V. & & & & & 14,6 & \\
\hline
\end{tabular}

-1) - Os valores seguidos pela mesma letra não diferem estatisticamente ao nível de $1 \%$ de probabilidade pelo teste de Tukey.

- *) - As letras $a, b$ referem-se à comparação entre as médıas de concentração dentro do fungicida.

${ }^{* *}$ ) - As letras $x, y, z$ referem-se ao teste entre as médias de fungicidas

\section{CONCLUSÕES}

1. Os frutos de pupunha sem sementes, mostraram-se mais resistentes à podridão negra e os frutos sem pedúnculo mostraram-se mais sensíveis à infecção. No teste de frutos com pedúnculo, o grau de infecção aumentou linearmente com o aumento da concentração do inóculo.

2. O fungicida Benomyl mostrou-se mais eficiente na inibição do desenvolvimento do fungo in vitro, em todas as concentrações testadas.

\section{SUMMARY}

Pupunha (Bactris gasipaes H.B.K.) is a palm distributed in almost all the humid tropics at south America and Central America. The pupunha fruits are rich in starch, lipids and proteins.

This crop presents a serious problem: after harveste the fruits are subject to the attack of black rot, caused by the fungus Thielaviopsis paradoxa. The fruit pulp becomes dark and smells as fermented In order to determine the spore concentration that induces black rot in pupunha, fruits with and without peduncle were inoculated with spore concentrations of $10^{7}, 10^{5}, 10^{3}$ e $10^{1}$ spores $/ \mathrm{ml}$. Fruits with peduncles were observed to require concentrations of $10^{7}$ spores/ $\mathrm{ml}$ to attain $100 \%$ fruit infection. The fruits with seed showed greater sensibility to infection. In another trial the fungicides: Benomyl, Triadimefon, Zineb and Maneb, were tested in vitro at the concentrations of $25,50,75$ e 100ppm in PDA medium (potato-Dextrose-Agar). Benomyl inhibited totally the growth of the fungus at all concentrations used. Triadimefon showed some efficiency at $100 \mathrm{ppm}$, while Zineb and Maneb were inefficient at all concentrations tested.

\section{REFERENCIAS BIBLIOGRÁFICAS}

AGUILLAR, J.A.E; MATOS, P.A.; CALDAS, R.C. \& NEIVA, L.P.A.

1981 - Controle químico de Thielaviopsis paradoxa em abacaxi. In: Anais do 6. Congresso Brasileiro de Fruticultura. Recife, Sociedade Brasileira de Fruticultura. p. 100-110.

CAMACHO, E.

1972 - El Pejibaye (Guilielma gasipaes (H.B.K.). L.H. Bailey). In: Simpósio Internacional sobre plantas de interesse econômico da flora amazônica. Belém, Brazil. p 101-106.

CHO, J.J.; ROHRBACH, K.G. \& APT. W.J.

1977 - Induction and chemical control of rot caused by Ceratacystis paradoxa on peneapples. Phytopathology, 67: 700-703.

FOURNIER, L.A.

1961 - Pejibaye (Guilielma gasipaes H.B.K.) L.H. Bailey). Turrialba, Costa Rica. IICA. 14p. (mimeografado).

INCAP \& IDNND

1961 e 1964 - Tabla de composición de alimentos para uso en America Latina. Centro Regional de Ayuda Tecnica y AID, México. p. 132.

PATIÑO, V.M.

1958 - El Cachipay o pejibaye (Guilielma gasipaes Bailey) e su papel en la cultura y en economia de los pueblos indigenas de America Tropical. America Indigena, México 18 (3): 177-204.

POPENOE, W. \& JIMENEZ, O.

1921 - The Pejibaye, a neglected foot plant of Tropical America. Journal of Heredity, 12 (4): 154-166.

SEIBERT, R.J.

1950 - The importance of palms to Latin America; pejibaye a notable example. Ceiba, Honduras 1 (2): $65-74$.

VARGAS, E. \& VILAPLANA, M.

1979 - Principales enfermedades del pejibaye observadas em Costa Rica. ASBANA, 3 (7): 8-9.

(Aceito para publicação em 06/11/81) 